\title{
Study to Evaluate Prevalence, Severity and Extension of Gingival Recession in the Adult Population of Ahmednagar District of Maharashtra State in India
}

\author{
Dr. Raju Anarthe ${ }^{1}$, Dr. Ameet Mani ${ }^{2}$, Dr. P.P. Marawar ${ }^{3}$ \\ 1: Sr. Lecturer, 2-Reader, 3-Professor and Head Dept. of Periodontology, Rural Dental College, Pravara \\ Institute of Medical Sciences, Loni- 413736 Maharashtra State, India
}

\begin{abstract}
The gingival recession was evaluated in 400 subjects aged more than 20 years, looking for dental treatment at Rural Dental College and Hospital, Loni, Maharashtra, India. Clinical examination was conducted by a single examiner and analysis of four surfaces (mesial, buccal, distal and lingual) was done. The gingival recession was measured in millimeters from the cementoenamel junction to the gingival margin with the help of UNC-15 periodontal probe. The recessions were scored by the criteria suggested by P. D. Miller. The study showed the prevalence, extension and severity of the gingival recession increased as age advances. Class I and Class II gingival recessions were the most prevalent in subjects less than 40 years old whereas from 40-49 years of age class III gingival recession was more common, in subjects older than 50 years, class IV gingival recession was more prevalent and it was mainly of generalized in distribution. The mandibular teeth displayed more surfaces with gingival recession than the maxillary teeth and the mandibular incisors were the most affected. Such high prevalence of gingival recession in adult subjects demonstrates that dental professionals should provide attention to the clinical significance, etiologic factors and management of gingival recession.
\end{abstract}

Key words: Gingival recession, UNC-15 periodontal probe, cementoenamel junction (CEJ), gingival margin.

\section{Introduction}

Gingival recession is the most common and undesirable condition of the gingiva and its prevalence increases with age. It is characterized by displacement of gingival margin apically from cement-enamel junction (CEJ) and exposure of root surface to the oral environment. Gingival recession (GR) can be defined as the exposure of the root surface due to apical shift of marginal gingiva [1], which is normally circumferential and 1 to $3 \mathrm{~mm}$ coronal to the cemento-enamel junction [2]. Gingival recession, either localized or generalized, is one of the clinical features of periodontal disease and is not considered as periodontal diagnosis itself. Gingival recession may be associated with one or more surfaces resulting in clinical attachment loss and root exposure, which can lead to clinical problems such as root surface hypersensitivity, root caries, cervical root abrasions, erosions, plaque retention and aesthetic concern. Gingival recession, therefore, can cause major functional and aesthetic problems [3], and should not be viewed as just a soft tissue defect, but rather as the destruction of both the soft and hard tissue because whenever soft tissue loss occurs, it is followed by hard tissue destruction i.e. cementum loss, alveolar bone loss.

Despite the common observation in adult subjects, the prevalence, extension and severity of gingival recessions presents considerable differences between study populations. Prevalence indicates the cases or occurrences of gingival recession; extension corresponds to the number of teeth affected by gingival recession; and severity signifies the total root surface exposed by the gingival recession, i.e. the linear vertical height of the gingival recession. Epidemiologic studies disclose significant information on prevalence and severity of a disease in a population and can be used to predict the disease pattern, progression, risk factors and treatment necessities. Many international and national studies have been conducted on gingival recession. Study of National Health Center (NHC) of the United States from 1988 to 1991 among 7447 unemployed Americans revealed a $15 \%$ prevalence of gingival recession equal to or more than $3 \mathrm{~mm}$. The prevalence varied from $0.5 \%$ in samples with 18 to 24 years of age to $45 \%$ in those over 65 years old [4].

More than 50\% of the population exhibit gingival recession [3]. Albandar and Kingman [5] found that, in the United States, the prevalence of gingival recession in people aged 30 years and older was $58 \%$. The prevalence of gingival recession increased with age, and men were more affected than women [6]. Gingival recession associated with facial surfaces of teeth which are facially positioned in the dental arch occurred in $40 \%$ of the subjects, 16 to 25 years of age and in $80 \%$ of the patients who are 36 to 86 years of age [6]. Susin et al. [7] found a high prevalence of gingival recession in a Brazilian population, with more than half of the individuals presenting $\geq 3 \mathrm{~mm}$ recession defects. In this study, gingival recession was associated with a high level of periodontal disease. The concern on these alterations is based on the potential consequences they may bring about, which affect not only oral health but also the general health. Within this circumstance, the clinical 
significance of gingival recession has been related to several conditions such as dentinal hypersensitivity; esthetic distress, especially when such lesions affect the anterior teeth; higher risk of root caries, abrasion and/or erosion lesions because of exposure of the root surface to the oral environment, besides an increase in the accumulation of dental plaque.

In addition to all clinical implications associated to the presence of gingival recession, such alterations have been regarded as the clinical manifestation of the disease and may be a significant feature in the diagnosis of susceptibility to periodontal disease [8]. Thus, perception of the occurrence of gingival recession in a given population is a basic need for their prevention and control and allows the appropriate planning of health centers based on information on the prevalence and severity of these lesions in order to establish correct and successful preventive programs that may control the onset and progression of gingival recession, as well as to avoid the complex local disturbances that may develop.

Therefore, the present study aimed at assessing the prevalence, extension and severity of gingival recessions in adult subjects attending dental camps organized by department of Periodontology and Public Health Dentistry, and Hospital of Rural Dental College, Loni.

\section{Material And Methods}

The study sample comprised 400 adult subjects aged more than 20 years, randomly selected from the patients by lottery system, attending the diagnosis and treatment camps organized by department of Periodontology and public health dentistry, Loni Maharashtra state, India. All participants were informed regarding the evaluation and an informed consent has been taken for participation in the study.

The subjects of both genders were divided in 4 groups according to the age range:

Group $1-20$ to 29 years: 100 patients;

Group $2-30$ to 39 years: 100 patients;

Group $3-40$ to 49 years: 100 patients;

Group 4 - above 50 years: 100 patients.

The selection criteria comprised age above 20 years and a mean number of 28 natural teeth, because large numbers of missing teeth interfere with the results of this study. The participants of the present study were evaluated by a single examiner, who was not submitted to any previous calibration.

The sample included 254 male and 146 female, adding up to 9,379 teeth. A UNC-15 (University of North Carolina-15) periodontal probe, Hu-Friedy was employed for evaluation of the gingival recession by a single examiner, which was recorded whenever there was more than $1 \mathrm{~mm}$ of root surface exposed.

Four surfaces were evaluated of each tooth: mesial, buccal, distal and lingual, and linear measurements were obtained from the cementoenamel junction to the gingival margin in the teeth presenting with gingival recession, in order to evaluate the vertical height of the gingival recession. In cases on which the cementoenamel junction was covered by calculus, hidden by a restoration or lost due to wasting disease or carious lesion, the location of such junction was estimated on the basis of the adjacent teeth. Three categories were established according to the apico-occlusal dimension of the root surface exposed by the gingival recession: small recessions less than $3 \mathrm{~mm}$ of root surface exposed; moderate recessions 3 to $4 \mathrm{~mm}$ of root surface exposed; advanced recessions more than $4 \mathrm{~mm}$ of root surface exposed to the oral environment. Gingival recession was recorded according to the P.D. Miller [9] classification of marginal tissue recession

- Class I-Marginal tissue recession without extending to the mucogingival junction without loss of bone or soft tissue in the interdental areas.

- Class II - Marginal tissue recession that extends to or beyond the mucogingival junction without loss of bone or soft tissue in the interdental areas.

- Class III-Marginal tissue recession that extends to or beyond the mucogingival junction in addition there is bone and/or soft tissue loss in the interdental areas and/or mild malocclusion.

- Class IV- Marginal tissue recession that extends to or beyond the mucogingival junction with severe bone and/or soft tissue loss in the interdental areas and /or severe tooth malposition.

\section{Results}

Gingival recession was observed in 304 subjects out of 400 subjects, corresponding to almost $76 \%$ of the total sample. From these individuals, 3316 displayed root surface exposure $\geq 1 \mathrm{~mm}$, corresponding to almost $29 \%$ of all teeth evaluated and adding up to 5792 sites with gingival recession (TABLE 1). Among the subjects without any such alterations, more than $89 \%$ belonged to the younger age range (20-29 years).This differed from the two older groups of the sample, on which almost all subjects presented with gingival recession (TABLE 1).

The increase in age lead to an increase in the mean number of teeth with gingival recession (TABLE 1); thus the subjects presenting more teeth with gingival recession aged more than 50 years and had more than $43 \%$ of their teeth affected (TABLE 1 ). 
In age groups 20-29 and 30-39 years, class I gingival recession is more prevalent i.e. about $74.91 \%$ and $74.39 \%$ respectively whereas there was slowly decrease in the class II, class III and class IV gingival recession (TABLE 2).

In age groups 40-49 years, there was slowly increase from class I gingival recession to class III gingival recession whereas only $8.26 \%$ subjects have class IV gingival recession (TABLE 2).

In older age groups more than 50 years, class III gingival recession and class IV gingival recession were more prevalent i.e. $35.24 \%$ and $49.95 \%$ whereas only $9.55 \%$ subjects presented with class II gingival recession and $5.24 \%$ showed class I gingival recession. (TABLE 2).

The mandibular central incisors were the teeth most frequently affected by root surface exposure, even though the maxillary and mandibular first molars also commonly displayed gingival recession (TABLE 3).

As regards the apico-occlusal height of the gingival recessions observed in the different age group, the severity of the root surfaces exposed, increased as older subjects were assessed (TABLE 4).

\section{Discussion}

The results of the present study agree with previous findings of the common occurrence of gingival recession in adult subjects. As observed in most epidemiological studies [10,11], the prevalence, extension and severity of gingival recession gradually increased with age.

This relationship between the occurrence of gingival recession and age may probably be because of the longer period of exposure to the etiologic and predisposing factors that cause gingival recession [12], associated to age related intrinsic changes, both local and systemic, besides the cumulative effects of the lesion itself [13]

Some of predisposing factors of gingival recession include [14]:

- Bone anatomy: Gingival recession significantly increases in root surfaces which are not covered with bone (dehiscence).

- Tooth position: Facially erupted tooth.

- Orthodontic movements could increase the probability of gingival recession.

- Mechanical trauma: Frequent impaction of foreign objects leads to gingival recession.

- Improper tooth brushing also predisposes the gingival recession to occur.

- Chemical trauma: Local cocaine use leading to gingival erosion is an example of chemical trauma.

- High frenum attachment is attributed to local gingival recession.

- Restorative dentistry: Subgingival restoration margins could increase plaque accumulation, gingival inflammation and bone resorption that lead to gingival recession.

- Calculus: Several studies have shown calculus is an important factor in gingival recession.

- Periodontal diseases result in connective tissue attachment loss and periodontal pocket formation or gingival recession.

- Smoking: Several studies have demonstrated marginal recession is greater in smokers than non-smokers. Furthermore, smoking could adversely affect root coverage surgeries and decrease the success rate in smokers compared to non-smokers.

- Removable prosthesis: Improper design of the removable dentures results in direct trauma and plaque retention, leading to gingival recession.

Table 1- Prevalence and extension of gingival recession according to age group

\begin{tabular}{|c|c|c|c|c|c|c|c|}
\hline \multicolumn{2}{|c|}{} & \multicolumn{3}{|c|}{ Prevalence } & \multicolumn{3}{c|}{ Extension } \\
\hline $\begin{array}{c}\text { Age } \\
\text { (years) }\end{array}$ & $\begin{array}{c}\text { Number of } \\
\text { subjects }\end{array}$ & $\begin{array}{c}\text { Total } \\
\text { Number } \\
\text { of teeth }\end{array}$ & $\begin{array}{c}\text { \% } \\
\text { Subjects }\end{array}$ & $\begin{array}{c}\text { Number } \\
\text { of teeth } \\
\text { with GR }\end{array}$ & $\begin{array}{c}\text { Mean } \\
\text { number of } \\
\text { Teeth with } \\
\text { GR/ } \\
\text { subjects }\end{array}$ & $\begin{array}{c}\text { Number } \\
\text { of sites } \\
\text { with GR }\end{array}$ & $\begin{array}{c}\text { Mean } \\
\text { number of } \\
\text { Sites of } \\
\text { GR/ } \\
\text { subjects }\end{array}$ \\
\hline $20-29$ & 100 & 2957 & 58 & 299 & 2.99 & 343 & 3.43 \\
\hline $30-39$ & 100 & 2899 & 68 & 781 & 7.81 & 1164 & 11.64 \\
\hline $40-49$ & 100 & 2878 & 87 & 1053 & 10.53 & 1984 & 19.84 \\
\hline$\geq 50$ & 100 & 2782 & 91 & 1183 & 11.83 & 2301 & 23.01 \\
\hline Total & 400 & 11516 & 76 & 3316 & 8.29 & 5792 & 14.48 \\
\hline
\end{tabular}


Study to Evaluate Prevalence, Severity and Extension of Gingival Recession in the Adult Population

Table 2- Scoring of the severity of gingival recession according to the parameters of P. D. Miller

\begin{tabular}{|c|c|c|c|c|c|c|c|c|c|}
\hline \multicolumn{9}{|c|}{ Class I } & \multicolumn{2}{c|}{ Class II } & \multicolumn{2}{c|}{ Class III } & \multicolumn{2}{c|}{ Class IV } & total \\
\hline $\begin{array}{c}\text { Age } \\
\text { Groups } \\
\text { years) }\end{array}$ & \multicolumn{2}{|c|}{} & \multicolumn{2}{|c|}{ Ningival Recession } & \\
\hline & No & No & \% & No & \% & No & \% & \\
\hline $20-29$ & 224 & 74.91 & 37 & 12.37 & 20 & 6.68 & 18 & 6.02 & 299 \\
\hline $30-39$ & 581 & 74.39 & 103 & 13.18 & 50 & 6.40 & 47 & 6.01 & 781 \\
\hline $40-49$ & 227 & 21.55 & 321 & 30.48 & 418 & 39.69 & 87 & 8.26 & 1053 \\
\hline$\geq 50$ & 62 & 5.24 & 113 & 9.55 & 417 & 35.24 & 591 & 49.95 & 1183 \\
\hline Total & 1094 & 32.99 & 574 & 17.31 & 905 & 27.29 & 743 & 22.40 & 3316 \\
\hline
\end{tabular}

Table 3 - Intraoral distribution of gingival recession

\begin{tabular}{|c|c|c|c|c|c|c|c|c|c|c|c|c|c|c|c|c|}
\hline$\%$ & 0.6 & 2.7 & 4.5 & 3.1 & 2.7 & 2.7 & 1.7 & 2.3 & 2.3 & 1.8 & 2.7 & 2.7 & 2.8 & 4.7 & 2.8 & 0.5 \\
\hline \multirow{2}{*}{ TEETH } & 18 & 17 & 16 & 15 & 14 & 13 & 12 & 11 & 21 & 22 & 23 & 24 & 25 & 26 & 27 & 28 \\
\cline { 2 - 38 } & 48 & 47 & 46 & 45 & 44 & 43 & 42 & 41 & 31 & 32 & 33 & 34 & 35 & 36 & 37 & 38 \\
\hline$\%$ & 0.6 & 2.8 & 4.8 & 3.0 & 2.8 & 3.1 & 5.7 & 6.5 & 6.8 & 5.6 & 3.0 & 2.8 & 2.9 & 4.8 & 3.5 & 0.7 \\
\hline
\end{tabular}

Table 4- Severity of gingival recession according to age groups

\begin{tabular}{|c|c|c|c|}
\hline $\begin{array}{c}\text { Age Group } \\
\text { (years) }\end{array}$ & $\begin{array}{c}\text { Gingival Recession } \\
<3 \mathrm{~mm}\end{array}$ & $\begin{array}{c}\text { Gingival Recession } \\
3-4 \mathrm{~mm}\end{array}$ & $\begin{array}{c}\text { Gingival Recession } \\
>4 \mathrm{~mm}\end{array}$ \\
\hline $20-29$ & 74.91 & 17.84 & 7.25 \\
\hline $30-39$ & 64.39 & 23.18 & 12.43 \\
\hline $40-49$ & 21.55 & 30.48 & 47.97 \\
\hline$\geq 50$ & 5.24 & 49.55 & 45.21 \\
\hline
\end{tabular}

Despite the controversies regarding the etiology of gingival recession, a local inflammatory process in different stages probably indicate the main cause of gingival recession, possibly triggered by a physical, chemical or bacterial aggression. Such condition is frequently reported as the combination of several factors classified in two major groups: factors predisposing to the area and occurrence of gingival recession - called predisposing factors; and factors that lead to onset of the disturbance - named precipitating factors, in charge of the induction of gingival recession. The main precipitating factors of gingival recession described in the literature are bacterial plaque[15], mechanical trauma because of hard-bristled toothbrushes, faulty brushing technique [16], frequency of toothbrushing, orthodontic therapy [17] and chemical trauma, primarily related to smoking [18]. However, besides the presence of precipitating factors, conditions that favor destruction of the marginal tissue must also be present for the occurrence of gingival recession. Such conditions are referred to on the literature as predisposing factors and are defined as local anatomic characteristics that favor the occurrence of gingival recession, such as: functionally unsatisfactory quantity and quality of attached gingiva [19], bone dehiscence [20], buccal tipping, high frenum attachment and traumatic occlusion [21].

There was a higher prevalence of recession in the mandibular anterior teeth, as observed in previous investigations [11], even though Gorman observed a similar prevalence on the maxilla [6], which the author assigned to thin or absent buccal plates. The larger occurrence of gingival recessions in the mandibular teeth is probably related to the characteristics of the keratinized mucosa, which is wider and also probably thicker in the maxilla than in the mandible, since a strong correlation has been observed between the quantity and quality of gingival tissue. Areas with deficient keratinized mucosa, especially as regards the thickness, have been demonstrated to be more susceptible to gingival recession, especially due to the smaller amount of connective tissue available on the area, what leads localized inflammatory reactions triggered by different processes to be able to affect the entire extension of the tissue, ultimately leading to gingival recession [19]

No differences were observed in the occurrence of gingival recession at the right and left sides, in agreement with the findings of Vehkalathi [11]. This result seems to indicate the lack of variation in the toothbrushing between individuals, either right- or left-handed, in relation to the traumatic effects of toothbrushing. As regards the teeth most frequently affected by gingival recession, no agreement is observed in the literature. Whereas some indicate the maxillary canines and premolars [22], other mention maxillary premolars and molars [13] and others indicate the mandibular central incisors and maxillary first molars [5] as the teeth most frequently affected by these alterations.

In the present study, the mandibular central incisors displayed the highest frequency of gingival recession. The mandibular lateral incisors and premolars and the maxillary and mandibular first molars were also commonly affected. It should be stressed that the distribution pattern of gingival recessions has been related to different etiologic factors. Gingival recessions on the mandibular incisors have been primarily associated to poor oral hygiene [23], whereas those on the premolars would be originated by traumatic toothbrushing [24]. 
Concerning the maxillary first molars, some authors believe the cause would be traumatic toothbrushing, whereas others state that it would be the outcome of a poor oral hygiene, demonstrated by the presence of dental plaque and calculus. These disagreements question the cause-effect relationship between gingival recession and dental calculus: would calculus be the etiologic factor or the consequence of gingival recession?

Even though dental calculus is destructive to the periodontal tissues, especially because of the additional retention it provides to the accumulation of dental plaque and consequent periodontal destruction as indicated by the gingival recession itself, its presence in sites with gingival recession is believed to be a consequence rather than a cause of root surface exposure, since surfaces with gingival recession are less favorable to self-cleansing than those without such alterations [24]. After accumulation in these areas, calculus might then act as a contributing factor in the progression and destruction of the marginal gingiva, yet probably it would not lead to onset of the process. It should be emphasized that localized gingival recession was often observed in teeth that apparently did not displayed plaque and calculus, especially in patients with good oral hygiene due to some mucogingival problems such as high frenum attachment, shallow vestibule and inadequate width of attached gingiva.

Despite the disagreement concerning the main tooth affected by gingival recession, the literature is unanimous to indicate the buccal surface as the site most frequently affected by such alterations [5], in agreement with the present study. The occurrence of recession in these areas has been primarily associated to improper toothbrushing habits, whereas localized gingival recession in the lingual and proximal aspects have been correlated to poor oral hygiene [10]. The higher prevalence, extension and severity observed in older subjects, in turn, suggests the growing effect of the lesion, associated to the longer period of exposure to the etiologic agents, which should be identified and removed as early as possible in order to reduce or even avoid worsening of the clinical condition.

\section{Conclusion}

Gingival recession is most commonly occurring periodontal condition in the rural population of the Maharashtra state of India. Gingival recession mainly occurs due to faulty oral hygiene practices by the patients, it causes alarming conditions like tooth sensitivity, food lodgment, plaque retention and esthetic problems. Below 40 years of the age class I and class II gingival recessions are more prevalent with less extension and severity whereas in the age group above 40 years, class III and class IV gingival recessions are more prevalent with more extension and severity. There is necessity to do the longitudinal study for exact assessment of prevalence, extension and severity gingival recession. Present study is conducted to assess gingival recession in the rural population so that dental practitioners and dental hygienist should take more effort to educate the patients regarding oral hygiene practices for the prevention of such conditions in periodontium and if condition starts occurring should be treated immediately to avoid the further complications.

\section{References}

[1]. Caranza FA, Takey HH, Muco-gingival surgery In: Caranza FA, Newman MG ( ${ }^{\text {th }}$ ed). Clinical Periodontology, chapter. 59, pages. 651-671, (Philadelphia, Saunders Company, 1996).

[2]. Caudill RF, Oringer RJ, Langer L, Esthetic Periodontics (Periodontal Plastic Surgery) In: Wilson TG, Kornman KS, Fundamentals of Periodontics, chapter 26, pages 497-518, (Chicago, Quintessence Publishing Co. Inc, 1996).

[3]. Kassab MM, Cohen RE, The etiology and prevalence of gingival recession, Journal of American Dental Association, 134 (2), 2003, 220-225.

[4]. Brown LJ, Brunelle JA, Kingman A, Periodontal status in the United States, 1988-1991: prevalence, extent, and demographic variation, Journal of Dental Research, 75, 1996, 672-83.

[5]. Albandar JM, Kingman A, Gingival recession, gingival bleeding and dental calculus in adults 30 years of age and older in the United States, Journal of Periodontology, 70(1), 1999, 30-43.

[6]. Gornman WJ, Prevalence and etiology of gingival recession, Journal of Periodontology, 38, (Jul/Aug), 1967, 316-322

[7]. Susin C, Haas AN, Oppermann RV, Gingival recession: epidemiology and risk indicators in a representative urban Brazilian population. Journal of Periodontology, 75, 2004, 1377-1386.

[8]. Beck JD, Koch GG, Characteristics of older adults experiencing periodontal attachment loss as gingival recession or probing depth

[9]. Journal of Periodontal Research, Jul; 29(4), 1994, 290-298.

[10]. Miller P. D., A classification of marginal tissue recession, International Journal of Periodontics and Restorative Dentistry, 5(2), $1985,8-13$

[11]. Löe H, Ånerud $\AA$, Boysen $\mathrm{H}$, The natural history of periodontal diseases in man: prevalence, severity and extent of gingival recession. Journal of Periodontology, Jun; 63(6), 1992, 489-95.

[12]. Vehkalahti M, Occurrence of gingival recession in adults, Journal of Periodontology, Nov, 60(11), 1989, 599-603.

[13]. Khocht A, Simon G, Person P, Denepitiya JL, Gingival recession in relation to history of hard toothbrush use, Journal of Periodontology Sept, 64(9), 1993, 900-905.

[14]. Serino G, Wennström JL, Lindhe J, Eneroth L, The prevalence and distribution of gingival recession in subjects with a high standard of oral hygiene, Journal of Clinical Periodontolology, Jan, 21(1), 1994, 57-63.

[15]. Solnit A, Stambaugh RV, Treatment of gingival clefts by occlusal therapy, International Journal of Periodontics and Restorative Dentistry, 3(3), 1983, 38-55.

[16]. Ericsson I, Lindhe J, Recession in sites with inadequate width of the keratinized gingiva: An experimental study in the dog, Journal of Clinical Periodontology, Feb, 11(2), 1984, 95-103. 
[17]. Checchi L, Daprile G, Gatto MRA, Pelliccioni A, Gingival recession and toothbrushing in an Italian School of Dentistry: a pilot study, Journal of Clinical Periodontolology, May, 26(5), 1999, 276-280.

[18]. Steiner GG, Pearson JK, Ainamo J, Changes of the marginal periodontium as a result of labial tooth movement in monkeys, Journal of Periodontology, June, 52(6), 1981, 314-20.

[19]. Martinez-Canut P, Lorca A, Magán R, Smoking and periodontal disease severity, Journal of Clinical Periodontology, Oct, 22(10), 1995, 734-749.

[20]. Kennedy JE, Bird WC, Palcanis KG, Dorfman HS, A longitudinal evaluation of varying widths of attached gingiva, Journal of Clinical Periodontology, Sept, 12(8), 1985, 667-75.

[21]. Löst C, Depth of alveolar bone dehiscences in relation to gingival recessions, Journal of Clinical Periodontology, Oct, 11(9), 1984, 583-589.

[22]. Watson PJC, Gingival Recession, Journal of Dentistry, Mar, 1984, 12(1):29-35.

[23]. Addy M, Mostafa P, Newcombe RG, Dentine hypersensitivity: the distribution of recession, sensitivity and plaque, Journal of Dentistry, Dec, 15(6), 1987, 242-248.

[24]. van Palenstein Helderman WH, Lembariti BS, van der Weijden GA, van't Hof MA, Gingival recession and its association with calculus in subjects deprived of prophylactic dental care, Journal of clinical Periodontology, Feb, 25(2), 1998, 106-111.

[25]. Joshipura KJ, Kent RL, DePaola PF, Gingival recession: Intra-oral distribution and associated factors, Journal of Periodontology, Sept, 65(9), 1994, 864-871. 